\title{
Pathological manifestations of the acanthocephalan parasite, Tenuiproboscis sp. in the mangrove red snapper (Lutjanus argentimaculatus) (Forsskål, 1775), a candidate species for aquaculture from Southern India
}

\author{
N.K. Sanil ${ }^{\text {a,* }}$, P.K. Asokan ${ }^{\text {b }}$, Lijo John ${ }^{\text {a }}$, K.K. Vijayan ${ }^{\text {a }}$ \\ a Fish Health Section, Marine Biotechnology Division, Central Marine Fisheries Research Institute, PB No. 1603, Cochin, 682018, India \\ ${ }^{\mathrm{b}}$ Calicut Research Center of CMFRI, West Hill P.O., Calicut, 673005, Kerala, India
}

\section{A R T I C L E I N F O}

\section{Article history:}

Received 17 September 2010

Received in revised form 14 October 2010

Accepted 19 October 2010

Available online $\mathrm{xxxx}$

\section{Keywords:}

Red snapper

Lutjanus argentimaculatus

Tenuiprobiscis sp.

Acanthocephala

Pathology

\begin{abstract}
A B S T R A C T
The study describes the pathological manifestations of the acanthocephalan, Tenuiproboscis sp. in the mangrove red snapper, Lutjanus argentimaculatus, a highly valued food fish along the southwest coast of India. The fish collected from Calicut, Cochin and Kannur harboured the acanthocephalan parasite, Tenuiproboscis sp. with up to $100 \%$ prevalence. Heavy infections with the parasites were observed in the posterior region of the intestine, almost blocking the lumen. At the site of parasite attachment, the surface of the intestine appeared thickened and the mucosal epithelium showed compression and abrasion. Intestinal folds were eroded along with thickening of lamina propria. The presoma of the parasites pierced the mucosal epithelium, lamina propria, muscle layers and serosa, reaching the peritoneal cavity, surrounded by a tunnel with collagenous fibers and granulocytes. Inflammation, granular tissue formation, connective tissue proliferation and associated host immune reactions were evident. Though the worms substantially damaged the architecture of the intestinal tissues, no apparent ill effects on the general health/condition of the fish were observed. The parasite was also recovered from Epinephelus malabaricus and Lates calcarifer. This is the first report of Tenuiproboscis sp. from $L$. argentimaculatus, E. malabaricus and $L$. calcarifer.
\end{abstract}

(C) 2010 Elsevier B.V. All rights reserved.

\section{Introduction}

Occurrence of disease conditions particularly due to parasites has become a major constraint in aquaculture (Bondad-Reantaso et al., 2005). Besides the direct losses caused by mortality, parasites have considerable impact on growth, resistance to other stressing factors, susceptibility to predation, marketability and pave way for secondary infections (Scholz, 1999; Lom and Dyková, 1992; Woo, 2006). Parasitic infections in fishes are common, especially in wild populations where ecological requirements for intermediate hosts and parasite transmission are met (Feist and Longshaw, 2008). Management of parasitic problems is the major limiting factor in finfish aquaculture in terms of profitability and environmental health (Mustafa et al., 2001; Costello, 2009; Burridge et al., 2010).

The mangrove red snapper (Lutjanus argentimaculatus) is a highly valued food fish in the tropical and sub-tropical countries (Liao et al., 1995). Though a common inhabitant of estuaries and coastal waters, it is never found in sufficient quantities to meet the commercial demand and the culture still depends on wild fry, the supply of which is

\footnotetext{
* Corresponding author. Fish Health Section, Marine Biotechnology Division, Central Marine Fisheries Research Institute, PB No. 1603, Ernakulam North P.O., Cochin, 682018, India. Tel.: + 91484 2394867; fax: + 914842394909.

E-mail address: nksanil@gmail.com (N.K. Sanil).
}

limited, seasonal and unpredictable. Despite these constraints, in recent years, aquaculture of the mangrove red snapper has become immensely popular in Southeast Asia and Australia due to its high market price (Emata and Borlongan, 2003). L. argentimaculatus is considered as a euryhaline, hardy and fast growing fish capable of tolerating stress and crowding (Leu et al., 2003). These attributes make it an ideal species for aquaculture. Most of the aquaculture production of $L$. argentimaculatus comes from Southeast Asia where they are reared in marine cages and brackish water ponds. In 2008, world production of $L$. argentimaculatus from capture fisheries was more than 17,563 tons while aquaculture production was recorded at 3502 tons (FAO, http://www.fao.org/fishery/species/3134/en).

Acanthocephalans are a group of endoparasitic helminths commonly found in both marine and freshwater fishes worldwide. They have a complex life cycle involving arthropods as intermediate hosts and vertebrates as definitive or paratenic hosts and are known to cause pathological conditions in many fin fishes (Nickol, 2006). The irreversible mechanical damage caused by the attachment of the armed proboscis affect the architecture of the intestinal tissues leading to pathological changes. Loss/degeneration of the intestinal villi, formation of granular tissues and capsule formation associated with host immune responses seriously affect the digestive and absorptive efficiency of the animal. In heavy infections they can cause occlusion of the gut and invasion/migration of the parasites into 
uncommon locations have also been reported (Nickol, 2006). Besides the drain of valuable nutrients, involvement of toxins and localized toxaemia has also been suggested by some authors (Holloway, 1966; Schmidt et al., 1974). But, diverse views exist regarding the intensity of damage caused by the parasites to the well being of the host and in many cases, apparent changes are not reflected in the general health/ condition of the host.

L. argentimaculatus is a common inhabitant of the estuaries along the coastal waters of southwest coast of India. Unlike other Asian countries, in India, commercial culture of red snapper is in its initial stages. Non availability of the fry limits the sustainability of aquaculture and hatchery production is the only option left which in turn necessitates a healthy broodstock. So far no information is available on the parasites and their effects on L. argentimaculatus from India. Preliminary investigations revealed the presence of heavy acanthocephalan infections in red snappers from the southwest coast of India. The present study was conducted to assess the pathological manifestations of the acanthocephalan infection in the juveniles and sub-adults of red snapper from selected estuaries along the southwest coast of India. Other aquacultured species like Epinephelus malabaricus and Lates calcarifer which shared the same habitat were also examined for acanthocephalan infections.

\section{Materials and methods}

\subsection{Sampling}

Juveniles and sub-adults of $L$. argentimaculatus were collected from Calicut (Moorad estuary), Cochin (Vembanad lake) and Kannur (Kattampally estuary) along the southwest coast of India. E. malabaricus was collected from Calicut (Moorad estuary) and Kannur (Kattampally estuary) while L. calcarifer was collected from Cochin (Vembanad lake) (Fig. 1).

The fishes ranging from 80 to $210 \mathrm{~g}$ were dissected, intestines removed and placed in physiological saline in petri dishes. The entire intestine was dissected open longitudinally and examined for the presence of acanthocephalan parasites under a Leica S6D stereozoom microscope (Leica, Wetzlar, Germany). The intestine along with the parasites was placed under refrigeration for a day for dislodging the attached parasites and for extending and everting their proboscis.
Parasites attached firmly to the walls/tissue of the intestine were dissected out with the aid of fine needles and forceps. The specimens were then fixed in cold $75 \%$ ethanol.

\subsection{Whole mounts}

For preparing whole mounts, specimen were pressed slightly between glass slides, fixed in AFA (alcohol-formol-acetic acid) overnight, stained with Semichon's acetocarmine stain and counter stained with fast green (Lasee, 2006).

\subsection{Scanning electron microscopy}

For Scanning electron microscopy, parasites were fixed in $2.5 \%$ glutaraldehyde followed by $1 \%$ Osmium tetroxide, dehydrated in acetone series, critical point dried, gold coated and observed under a Scanning electron microscope (JEOL 6490 LA, Japan) at an acceleration voltage of $8 \mathrm{kv}$ and electron micrographs taken.

\subsection{Histopathology}

For histopathology work, infected intestines were fixed in $10 \%$ neutral buffered formalin, dehydrated in ethanol series, cleared, embedded in paraffin and $6 \mu \mathrm{m}$ thick sections were taken using a Leica Microtome (Leica, Wetzlar, Germany). The sections were stained using Harris Haematoxylin and Eosin and examined under a light microscope (Nikon Eclipse 80i, Tokyo, Japan) and photomicrographs were taken.

\section{Results}

\subsection{Prevalence and intensity}

The examination of the intestine of $L$. argentimaculatus revealed the presence of heavy infection with the parasite (Fig. 2a). All the fish collected from Moorad estuary (Calicut) were found to be infected, while those from Vembanad lake (Cochin) and Kattampally estuary (Kannur) showed 74\% and 57\% prevalence respectively. Infections were recorded from E. malabaricus from Calicut and Kannur with a prevalence of $100 \%$ and $50 \%$ respectively. The worms were yellow to
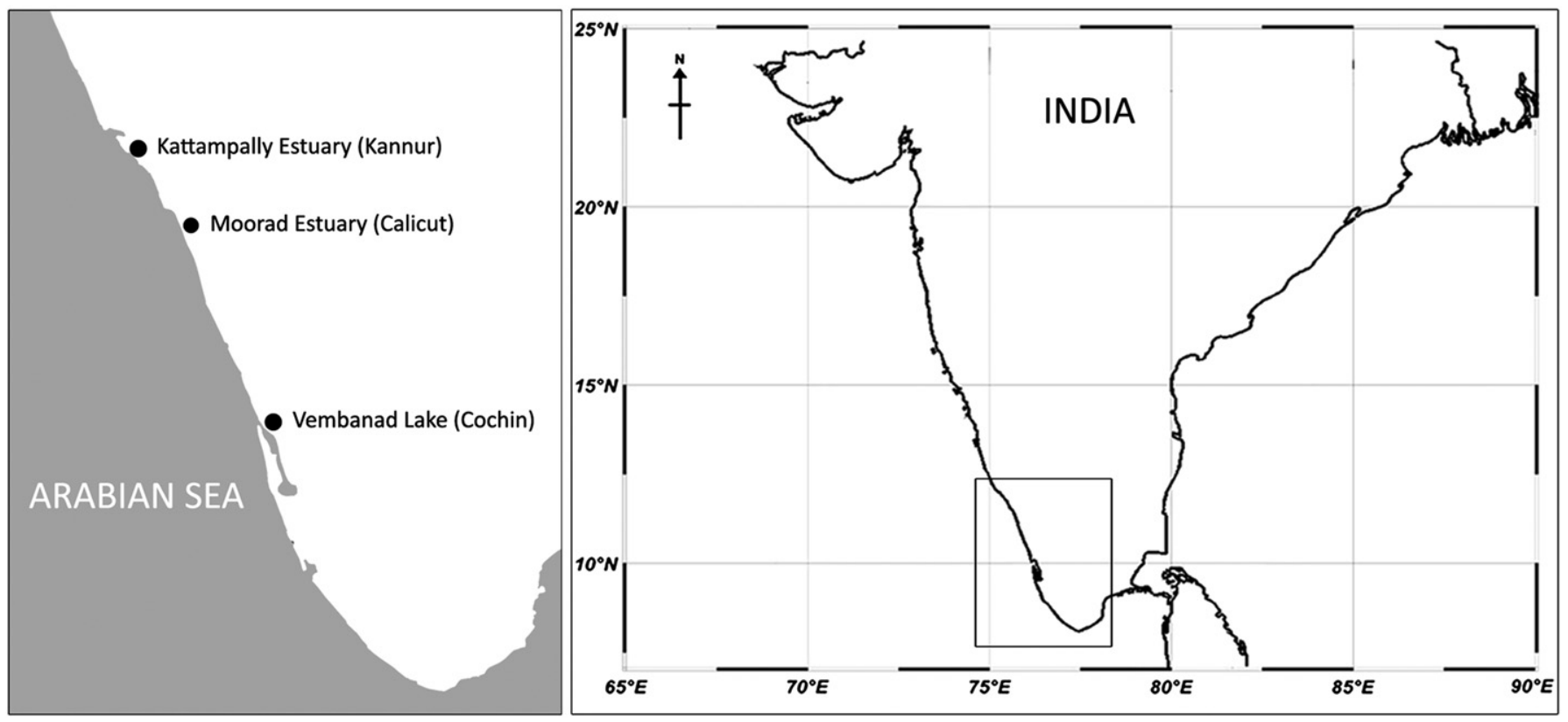

Fig. 1. Map of the southwest coast of India showing the sites of collection. 

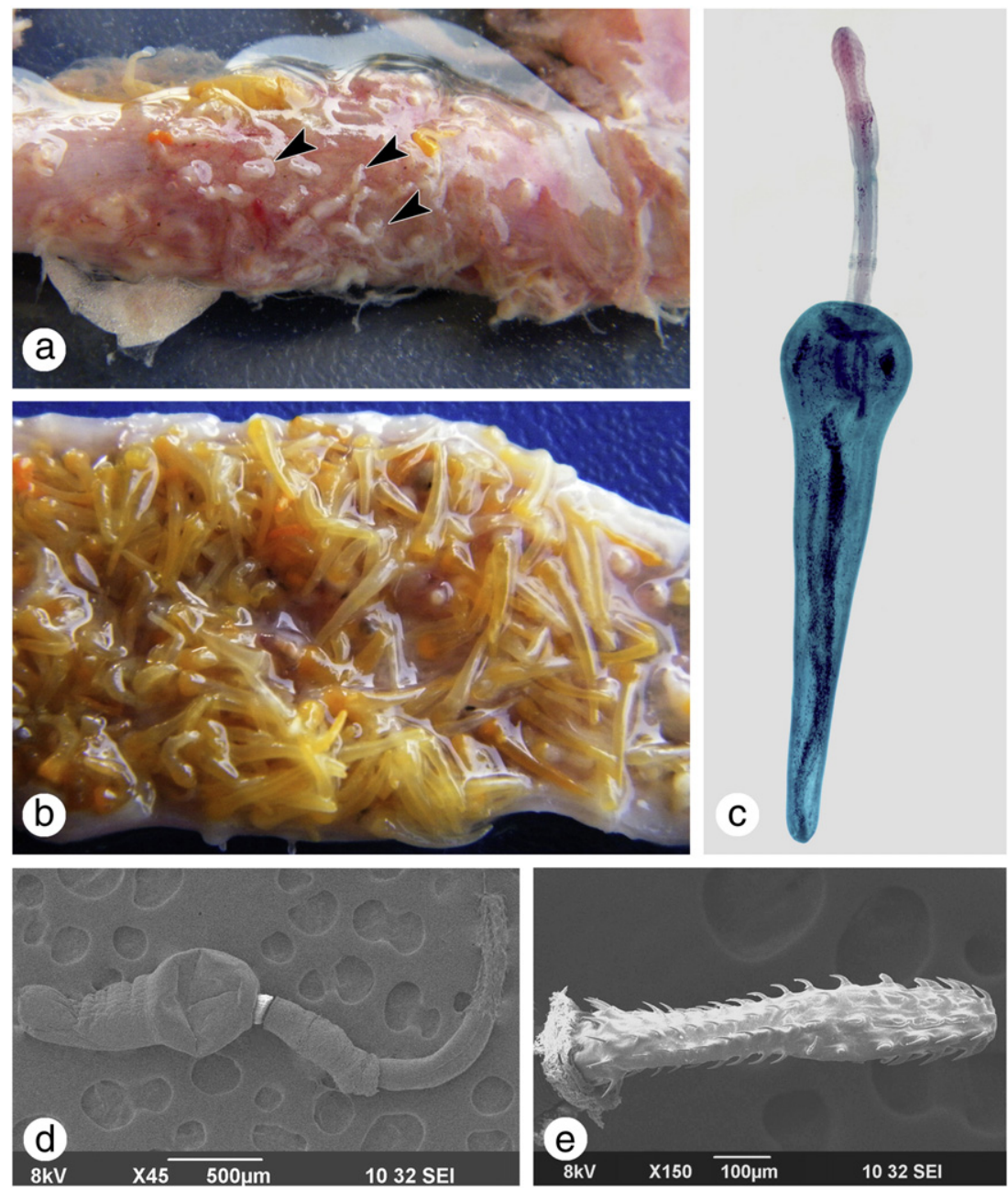

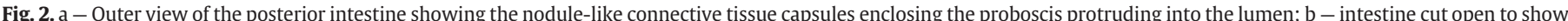

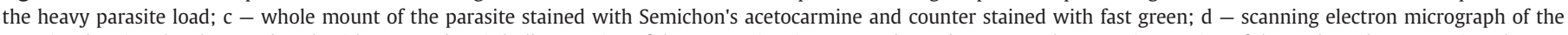

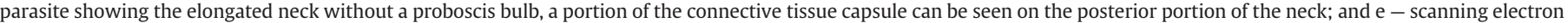
micrograph of the heavily armed proboscis. (For interpretation of the references to colour in this figure legend, the reader is referred to the web version of this article.)

orange in colour and were seen attached to the posterior region of the intestine (Fig. 2b). The intensity of infection varied from moderate to very heavy with the numbers varying from 4 to 268 in $L$. argentimaculatus. In E. malabaricus collected from Calicut, the intensity of infection varied from moderate to heavy (18 to 213) while at Kannur it was low (4). Only 1 specimen of $L$. calcarifer was examined from Cochin and intensity of infection was very low with only 2 parasites recorded (Table 1 ).

\subsection{Morphology}

The metasoma of the parasite was cylindrical, with a bulb like swelling at its anterior and tapering towards the posterior. Possesses

Table 1

Prevalence of Tenuiproboscis sp. infection in different geographical regions and hosts.

\begin{tabular}{llllc}
\hline Host & $\begin{array}{l}\text { Place of } \\
\text { collection }\end{array}$ & $\begin{array}{l}\text { No. of fish } \\
\text { examined }\end{array}$ & $\begin{array}{l}\text { No. of fish } \\
\text { infected }\end{array}$ & $\begin{array}{l}\text { Prevalence of } \\
\text { infection (\%) }\end{array}$ \\
\hline Lutjanus argentimaculatus & Calicut & 25 & 25 & 100 \\
& Cochin & 19 & 14 & 74 \\
& Kannur & 7 & 4 & 57 \\
Epinephelus malabaricus & Calicut & 3 & 3 & 100 \\
& Kannur & 2 & 1 & 50 \\
Lates calcarifer & Cochin & 1 & 1 & 100
\end{tabular}

an elongated neck with a heavily armed proboscis, but without a proboscis bulb (Fig. 2c and d). Males were smaller than females. Scanning electron microscopic studies showed that the proboscis was heavily armed with 14-16 longitudinal rows of spines (Fig. 2e). The anterior spines were larger in size which decreased progressively towards the posterior but the posterior most row of spines was again larger. Based on the morphological features the parasite has been identified as Tenuiproboscis sp.

\subsection{General pathology}

The heavily infected, posterior region of the intestine appeared swollen with the anterior ends of some worms projecting into the peritoneal cavity enclosed in a connective tissue capsule. A cross section of the intestine showed that the intestine was packed with parasites, almost blocking the intestinal lumen (Fig. 3a). At the site of parasite attachment, the surface of the intestine appeared thickened (Fig. 3b).

In E. malabaricus the parasites were found to occupy the entire stretch of the intestine posterior to the stomach and the intensity of infection was very heavy. The proboscis of most of the parasites enclosed in a capsule was seen projecting into the peritoneal cavity in a melanised condition, while in L. argentimaculatus it was less. 

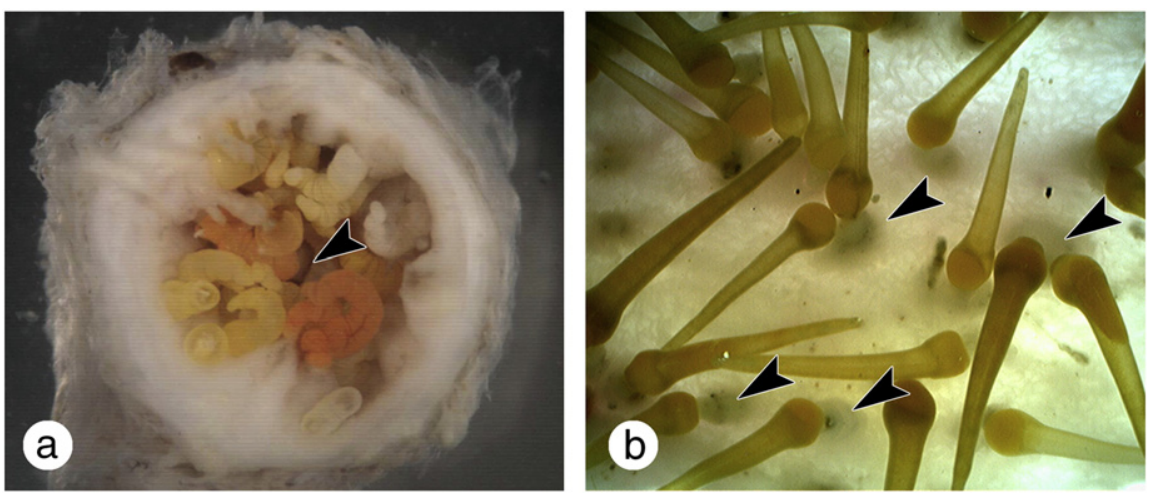

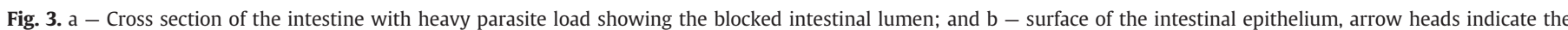
thickenings at the site of parasite attachment.

\subsection{Histopathology}

Histopathological studies revealed severe damage to the wall of the intestine (Fig. 3a). The mucosal epithelium of the intestine opposed to the metasoma of the worm showed compression, abrasion and desquamation (Fig. 4a and b) and the lamina propria appeared thickened (Fig. 4c). Hyperplasia of the intestinal villi and lamina propria were observed (Fig. 4d). Intestinal folds at the sites of parasite attachment had their tips eroded and appeared flattened along with increased mucus production (Fig. 4e). Degeneration and necrosis of the mucosal epithelium was evident and in many areas they were totally eroded, drastically reducing the absorptive area available for the digestive and absorptive functions of the animal. In intestinal villi near the site of parasite attachment, the epithelial cells were found detached, capillaries were ruptured and clumps of RBC seen lying free in the lumen (Fig. $4 \mathrm{f}$ and g). Changes in microvasculature including enlargement and proliferation of blood vessels and dilation of lymphatic vessels were observed in the intestinal villi with hyperplasia. In some of the capillaries the numbers of RBCs visible were very low (Fig. 4h).

The presoma of the parasites were found to pierce the mucosal epithelium, lamina propria, stratum granulosum, muscularis and serosa of the wall of the intestine forming a tunnel surrounded with collagenous fibers and granulocytes (Fig. 5a). Inflammation, granular tissue formation, connective tissue proliferation and associated host immune reactions were evident in the tissues. Aggregation of lymphocytes and the presence of large number of granulocytes and fibroblasts suggest inflammatory responses (Fig. 5b, c, d and e). Though the parasite was enclosed in a fibrous capsule of host origin, the integument of the parasite appeared to be unaffected by the inflammatory responses mounted by the host's immune system (Fig. 5f). The large, last row of spines on the proboscis were seen anchored firmly in the surrounding connective tissue capsule (Fig. 5g). The neck region of the parasite was particularly long, in many cases the proboscis was seen traversing the entire breadth of the intestinal wall and reaching the peritoneal cavity, enclosed in a fibrous connective tissue jacket of host origin (Fig. 5h). The worms did not produce any visible ill effects on the general health of the animals. However, histopathological studies revealed severe pathological changes and the mechanical damage caused by the worms have totally destroyed the architecture of the intestinal tissues (Fig. 6).

\section{Discussion}

This is the first report of a Tenuiproboscis sp. infecting $L$. argentimaculatus, causing serious pathological conditions in the infected fish. Generally in parasitic infections, the host immune system reacts in different ways to the parasite stages and the cellular responses invariably attempts to isolate and destroy the parasites. The most severe pathology is often a combination of efficient parasite replication and excessive host response (Feist and Longshaw, 2008).

Histopathological changes in fish intestines due to acanthocephalan infections depend on various factors such as species of parasite and host nature of the infected tissues and host-parasite interactions. The nature and thickness of the various tissue layers, length of the neck and proboscis, presence or absence of a proboscis bulb and the nature of spination also affect the pathological outcome. The mechanical destruction to the host's intestinal tissue is usually followed by host immune responses like proliferation of fibroblasts and granular cell infiltration around the invader, resulting in the formation of a collagenic capsule around it (Schelhaas, 1980), which is very much evident in the present study.

The pathology of acanthocephalan parasites in fishes especially with reference to Pomphorhynchus laevis has been well documented (Hine and Kennedy, 1974; Mcdonough and Gleason, 1981; Wanstall et al., 1986; Dezfuli, 1991). Usually in acanthocephalan infections, pathology appears to be negligible when parasites are attached to the epithelial mucosa only but deeply embedded forms like Pomphorhynchus spp. can cause serious pathological conditions resulting in extensive granuloma and subsequent fibrosis (McDonough and Gleason, 1981; Kabata, 1985). Extensive inflammation, peritonitis due to perforation of the gut and systemic clinical changes will occur only in massive infections, most often in farmed fish (Bullock, 1963).

In the present case, the parasite, Tenuiproboscis sp. has considerably damaged the tissue architecture of the host's intestine. When compared to the normal, the infected posterior region of the intestine appeared swollen and flabby which can be attributed to the structurally weakened circular and longitudinal muscle layers of the intestine succumbing to the pressure from the heavy load of parasites inside the lumen. In heavy infections, the intestine appeared to be packed with parasites, almost blocking the intestinal lumen, which will adversely affect the movement of digested materials within the intestine and the absorption of nutrients. de Buron and Nickol (1994), reported occlusion and significant distention of caeca in Lepomis cyanellus infected with the acanthocephalan Leptorhynchoides thecatus.

The wall of the intestine in fishes is composed of an inner epithelium, lamina propria, stratum compactum, stratum granulosum, circular and longitudinal muscle layers and an outer serosa, while the intestinal folds are composed of columnar epithelium and a core of lamina propria (McDonough and Gleason, 1981). In $L$. argentimaculatus stratum compactum was not observed but stratum granulosum was present. Unlike other species of acanthocephalans, Tenuiproboscis sp. possesses a long neck and penetrates deep into the wall of the intestine with the heavily armed proboscis often projecting into the peritoneal cavity. The pronounced thickening of the intestinal surface around the site of attachment of the parasites could be due to 


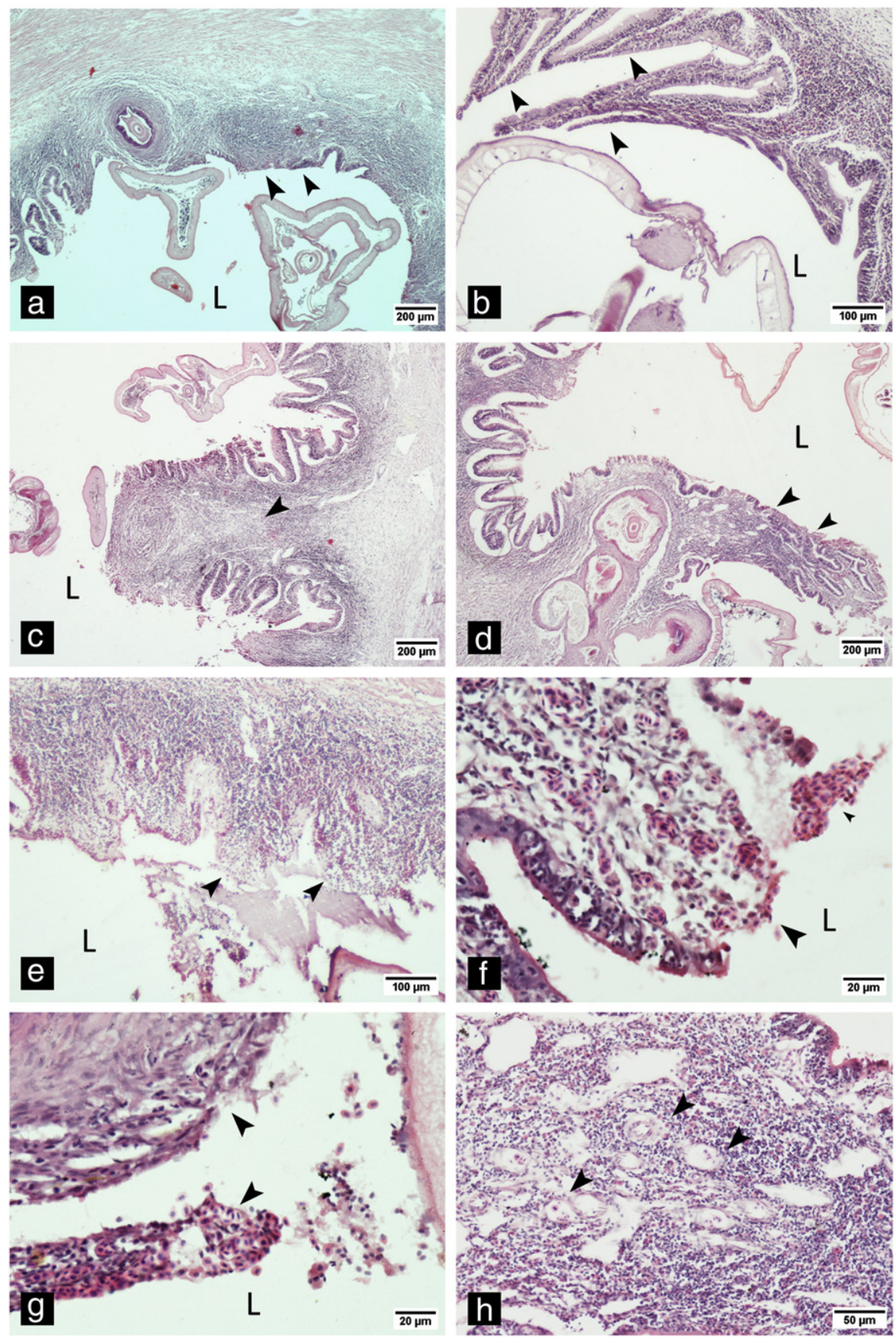

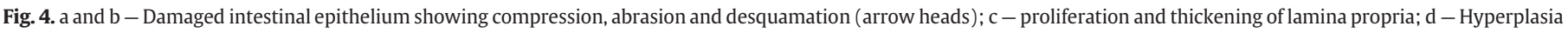

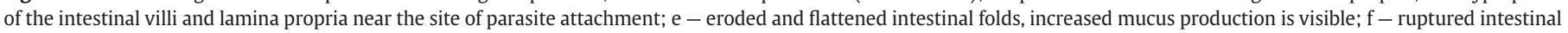
epithelium; $\mathrm{g}$ - detached epithelium along with clumps of RBC lying free in the lumen; and $\mathrm{h}$ - proliferation of blood vessels in the hyperplasic intestinal villi. $\mathrm{L}-$ lumen.

hyperplasia. Yildiz et al. (2004) have also observed a marked thickening of the lamina propria and localized inflammation in $P$. laevis infection in tench. The nature of the pathological changes observed in the intestinal tissues, viz. compression of mucosal epithelium at the point of attachment and the tissue damage to the various layers of the intestine is in perfect agreement with the changes described by Wanstall et al. (1986) for P. laevis infection in Salmo gairdneri. George and Nadakal (1981) have also reported degeneration and necrosis of the mucosal epithelium and excessive mucus secretion in Rachycentron canadum infected with the acanthocephalan, Serrasentis nadakali. Changes in microvasculature were observed in hyperplastic intestinal villi. Remodeling of vasculature is a common feature encountered in inflammatory reactions. Jackson et al. (1997) observed that inflammatory state can promote angiogenesis and many inflammatory mediators are direct or indirect stimulants of angiogenesis. The presence of low numbers of RBCs in some of the capillaries can be attributed to the dilation or enlargement of the vessels. Chronic inflammation is associated with blood vessel proliferation and enlargement and changes in vessel phenotype (Thurston et al., 1998).

The presence of fibrous inflammation tissue with immunologically active cells which later contributes to the formation of the fibrous capsule around the parasite indicates strong host responses. Fig. 6, a reconstructed image of the cross section of the infected region of the intestine clearly shows the extent of tissue damage to the intestinal folds and muscle layers and only a small portion of the villi remained intact. Parasite induced fibrosis in the intestinal wall along with the associated biochemical reactions will induce loss of gut motility 

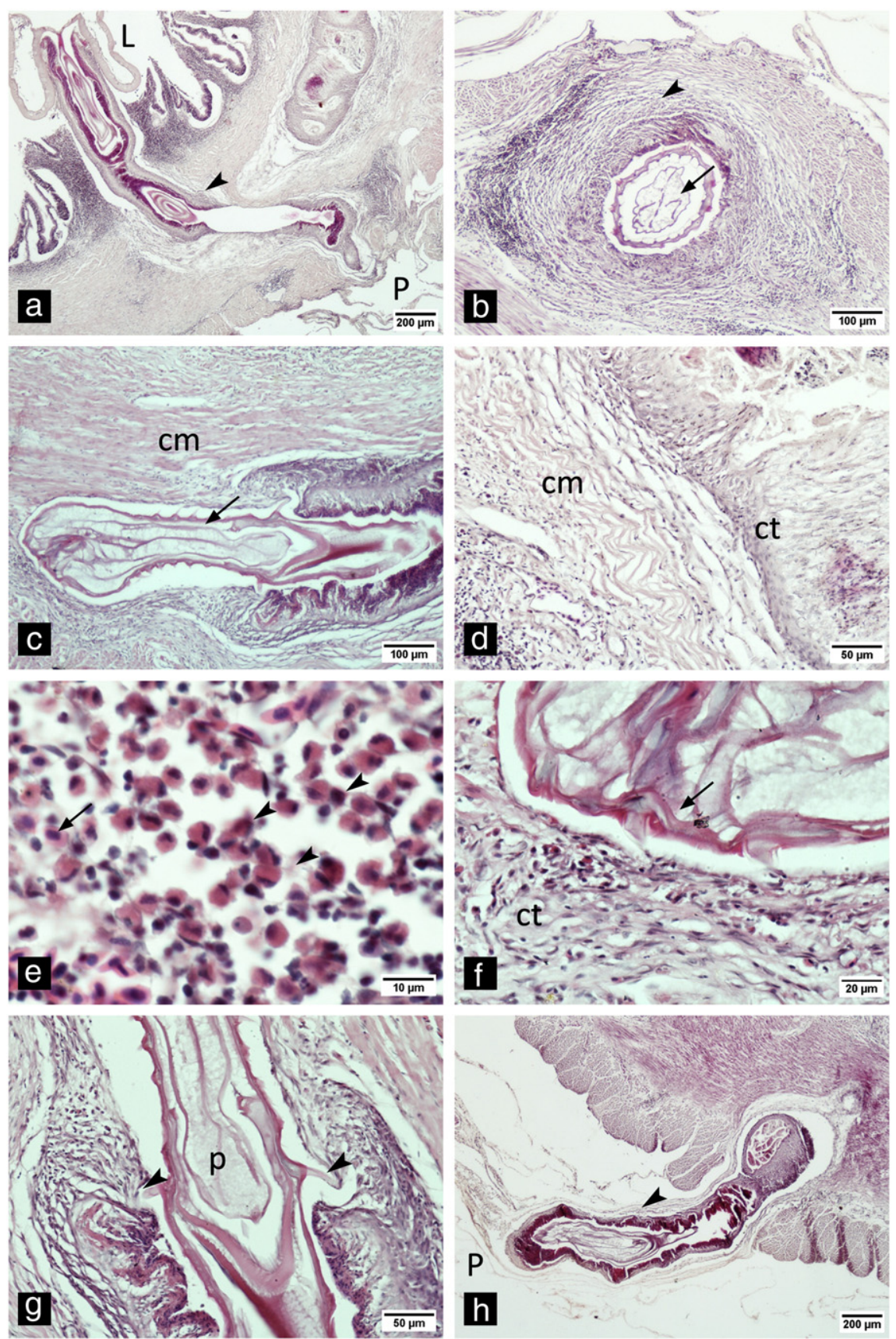

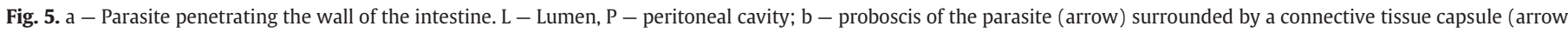

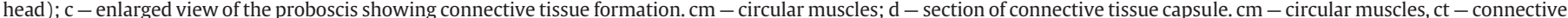

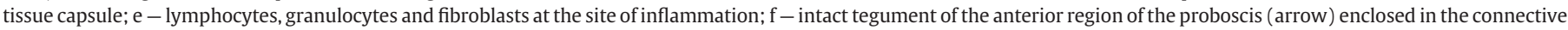

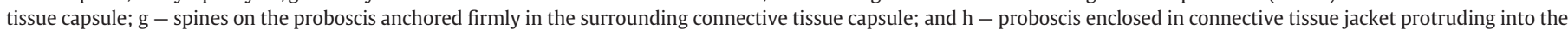
peritoneal cavity.

(Nickol, 2006). Further, severe damage to the intestinal folds will drastically reduce the absorptive area available for the digestive and absorptive functions of the animal.

The presence of encapsulated proboscis projecting into the peritoneal cavity is a function of the thickness and nature of the wall of the intestine and the melanised host capsule around the proboscis indicates host immune response, however in the present case, the surface of the proboscis appeared to be unaffected by the host's immune responses. The depth of penetration of some species can vary with different host species (Taraschewski, 1988) and this explains the observation of large number of worms projecting into the peritoneal cavity in E. malabaricus.
Taraschewski (2000) has observed that the pathogenicity of acanthocephalans is mainly caused by two factors, density of worms and depth of parasite penetration into the host tissues. Though the pathological effects are localized around individual worms, in the present case with unusually high parasite load, total destruction of the tissue architecture due to the collective pathological changes had occurred. However, the fish appeared healthy without any clinical manifestations and this observation is in agreement with the views of Hine and Kennedy (1974). In heavy infections the amount of nutrients drained by these worms may be of considerable physiological consequence to the host animals. Severe irreversible damage to the intestinal villi will drastically reduce the absorptive area available for 


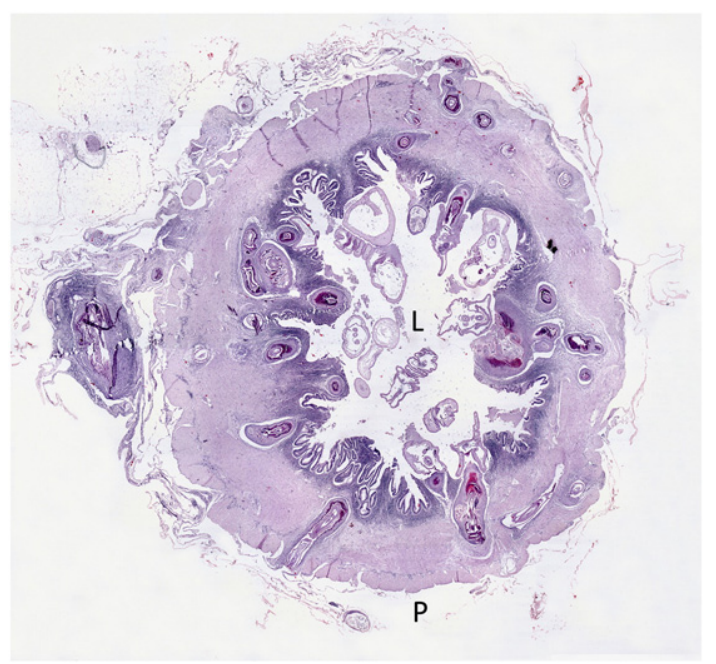

Fig. 6. Reconstructed image of the cross section of the intestine showing the extent of tissue damage to the intestinal folds and muscle layers, note that only a small portion of the villi remains intact. $\mathrm{L}$ - Lumen, $\mathrm{P}$ - peritoneum.

the normal digestive and absorptive functions of the animal while the damages associated with the tissue reactions in the wall of the intestine will alter the nature of the tissues, affecting its functional efficiency and the overall health status of the fish.

Tenuiproboscis was first reported from Japan with T. misgurni as type species (Yamaguti, 1935); subsequently 6 more species were reported from the Indian subcontinent (Gupta and Sinha, 1989, 1991; Gupta and Naqvi, 1993; Bhattacharya, 2007; Saxena and Gupta, 2007). Studies on the parasites of red snapper from the neighboring countries did not report any Tenuiproboscis sp. infections (Arthur and Ahmed, 2002; Chandra, 2006; Ghaffar, 2007). This is the first study on the detailed pathological manifestations of Tenuiproboscis sp. and is also the first report of the parasite from $L$. argentimaculatus, $E$. malabaricus and L. calcarifer. A prevalence of $100 \%$ in L. argentimaculatus, and E. malabaricus combined with high intensity of infections in Moorad estuary, Calicut indicates that Tenuiproboscis sp. is less host specific and the ecological requirements for intermediate hosts and parasite transmission are met, favoring the establishment of the parasite. Heavy infections with Tenuiproboscis sp. capable of causing irreversible damage to the intestinal tissues can seriously affect the health and quality of the L. argentimaculatus broodstock and thereby making the fish unfit for hatchery production. As currently the hatchery production of fin fishes in the region depends solely on brood stock sourced from the wild, further studies are required to understand the intermediate host and life cycle pattern of the parasite and to elucidate possible management measures.

\section{Acknowledgement}

The authors wish to thank the Director, CMFRI, Cochin, for providing the facilities in undertaking this work. We also thank Dr. K.C. George for his valuable suggestions during the preparation of the manuscript.

\section{References}

Arthur, J.R., Ahmed, A.T.A., 2002. Checklist of the Parasites of Fishes of Bangladesh. FAO Fisheries Technical Paper. No. 369/1. Rome, FAO. 77 pp.

Bhattacharya, S.B., 2007. Handbook on Indian Acanthocephala. Zoological Survey of India, Kolkata, pp. 1-255.

Bondad-Reantaso, M.G., Subasinghe, R.P., Arthur, J.R., Ogawa, K., Chinabut, S., Adlard, R., Tan, Z., Shariff, M., 2005. Disease and health management in Asian aquaculture. Vet Parasitology 132, 249-272.

Bullock, W.L., 1963. Intestinal histology of some salmonid fishes with particular reference to the histopathology of acanthocephalan infections. Journal of Morphology 112, 23-44.
Burridge, L., Weis, J.S., Cabello, F., Pizarro, J., Bostick, K., 2010. Chemical use in salmon aquaculture: a review of current practices and possible environmental effects. Aquaculture 306, 7-23.

Chandra, K.J., 2006. Fish parasitological studies in Bangladesh: a review. J. Agric. Rural. Dev. 4 (1\&2), 9-18.

Costello, M.J., 2009. The global economic cost of sea lice to the salmonid farming industry. Journal of Fish Diseases 32, 115-118.

de Buron, I., Nickol, B.B., 1994. Histopathological effects of the acanthocephalan Leptorhynchoides thecatus in the ceca of the green sunfish, Lepomis cyanellus. Transactions of the American Microscopical Society 113, 161-168.

Dezfuli, B.S., 1991. Histopathology in Leuciscus cephalus (Pisces: Cyprinidae) resulting from infection with Pomphorhynchus laevis (Acanthocephala). Parasitol. 33, 137-145.

Emata, A.C., Borlongan, I.G., 2003. A practical broodstock diet for the mangrove red snapper, Lutjanus argentimaculatus. Aquaculture 225, 83-88.

FAO. Species Fact Sheets Lutjanus argentimaculatus (Forsskål, 1775) Fisheries and Aquaculture Department, http://www.fao.org/fishery/species/3134/en.

Feist, S.W., Longshaw, M., 2008. Histopathology of fish parasite infections - importance for populations. Journal of Fish Biology 73, 2143-2160.

George, P.V., Nadakal, A.M., 1981. Observations on the intestinal pathology of the marine fish, Rachycentron canadus (Gunther) infected with the acanthocephalid worm Serrasentis nadakali (George \& Nadakal, 1978). Hydrobiologia 78, 59-62.

Ghaffar, R.A., 2007. Seasonal Variation and Histopathology of Helminth Parasites in the Fish Lutjanus argentimaculatus (Forskal, 1775), Red Snapper. Ph.D. Thesis, University of Karachi.

Gupta, S.P., Naqvi, M., 1993. On four species of the genus Tenuiproboscis Yamaguti, 1935 (Acanthocephala: Pomphorhynchidae) from marine fishes of Kerala. Indian Journal of Helminthology 44 (1), 17-26.

Gupta, V., Sinha, G., 1989. On a new Acanthocephala Tenuiprobocis guptai sp. nov. (Pomphorhynchidae, Yamaguti, 1939) from a marine fish Gerres setifer Ham. from Calcutta, West Bengal. Indian. Journal of Helminthology 41 (2), 104-107.

Gupta, V., Sinha, G., 1991. On some acanthocephalan parasites from marine fishes of Bay of Bengal, Puri coast, Orissa. Indian Journal of Helminthology 43 (2), 108-118.

Hine, P.M., Kennedy, C.R., 1974. Observation on the distribution, specificity and pathogenicity of the acanthocephalan Pomphorhynchus laevis. Journal of Fish Biology 6, 521-533.

Holloway Jr., H.L., 1966. Prosthorhynchus formosum (Van Cleave 1918) in song birds, with notes on acanthocephalans as potential parasites of poultry in Virginia. Virginia Journal of Science, New Series 17, 149-154.

Jackson, J.R., Seed, M.P., Kircher, C.H., Willoughby, D.A., Winkler, J.D., 1997. The codependence of angiogenesis and chronic inflammation. The FASEB Journal 11, 457-465.

Kabata, Z., 1985. Parasites and Diseases of Fish Cultured in the Tropics, 1st Edition. Taylor \& Francis, London and Philadelphia. 318 pages.

Lasee, B., 2006. National Wild Fish Health Survey - Laboratory Procedures Manual, Chapter 8 - Parasitology, Section 1, U.S. Fish and Wildlife Service, Washington DC, 3.1 edition., pp. 1-22.

Leu, M.Y., Chen, I.H., Fang, L.S., 2003. Natural spawning and rearing of mangrove red snapper, Lutjanus argentimaculatus, larvae in captivity. The Israeli Journal of Aquaculture - Bamidgeh 55 (1), 22-30.

Liao, I.C., Su, M.S., Chang, S.L., 1995. A Review of the Nursery and Grow-out Techniques of High-value Marine Finfishes in Taiwan. In: Main, K.L., Rosenfeld, C. (Eds.), Culture of High-Value Marine Fishes. Oceanic Institute, Hawaii, pp. 121-137.

Lom, J., Dyková, I., 1992. Protozoan Parasites of Fishes. Developments in Aquaculture and Fisheries Science, vol. 26. Elsevier. 315 pp.

Mcdonough, J.M., Gleason, L.N., 1981. Histopathology in the rainbow darter, Etheostoma caeruleum, resulting from infections with the acanthocephalans, Pomphorhynchus bulbocolli and Acanthocephalus dirus. The Journal of Parasitology 67, 403-409.

Mustafa, A., Rankaduwa, W., Campbell, P., 2001. Estimating the cost of sea lice to salmon aquaculture in eastern Canada. The Canadian Veterinary Journal 42 January 2001.

Nickol, B.B., 2006. Phylum Acanthocephala, In: Woo, P.T.K. (Ed.), Fish Diseases and Disorders, Second Edition. : Protozoan and Metazoan Infections, Vol. I. CAB International, Wallingford, UK, pp. 444-465.

Saxena, A.M., Gupta, R., 2007. On a new species of the genus Tenuiproboscis meyeri from a marine fish Scatophagus argus (Cuv. \& Val.) at Deegha, west Bengal. Indian Journal of Helminthology (NS) 25, 35-40.

Schelhaas D.P., 1980. Comparative Histopathology of Acanthocephan Infections in Some Freshwater Fishes. M.Sc. Thesis, University of North Dakota.

Schmidt, G.D., Walley, H.D., Wijek, D.S., 1974. Unusual pathology in a fish due to the acanthocephalan Acanthocephalus jacksoni Bullock, 1962. The Journal of Parasitology 60, 730-773.

Scholz, T., 1999. Parasites in cultured and feral fish. Veterinary Parasitology 84 (3-4), 317-335.

Taraschewski, H., 1988. Host-parasite interface of fish acanthocephalans. I. Acanthocephalus anguillae (Palaeacanthocephala) in naturally infected fishes: LM and TEM investigations. Diseases of Aquatic Organisms 4, 109-119.

Taraschewski, H., 2000. Host-parasite interactions in Acanthocephala: a morphological approach. Advances in Parasitology 46, 1-179.

Thurston, G., Murphy, T.J., Baluk, P., Lindsey, J.R., McDonald, D.M., 1998. Angiogenesis in mice with chronic airway inflammation strain-dependent differences. The American Journal of Pathology 153 (4), 1099-1112.

Wanstall, S.T., Robotham, P.W.J., Thomas, J.S., 1986. Pathological changes induced by Pomphorhynchus laevis Müller (Acanthocephala) in the gut of rainbow trout, Salmo gairdneri Richardson. Zeitscrift. Parasitenkd. 72, 105-114.

Woo, P.T.K., 2006. Fish Diseases and Disorders, Second Edition. Protozoan and Metazoan Infections, Vol. I. CAB International, Wallingford, UK. 808 pp.

Yamaguti, S., 1935. Studies on the helminth fauna of Japan. Part 8. Acanthocephala. Japanese Journal of Zoology 6, 247-278. 
Yildiz, K., Kabackci, N., Yarim, M., 2004. Pathological changes of tench intestines infected with Pomphorhynchus laevis. Revista de Medicina Veterinaria 155 (2), 71-73.

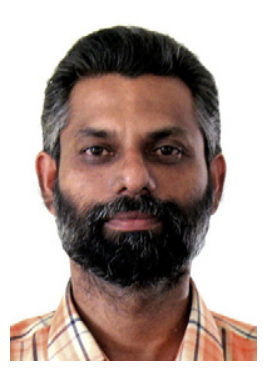

Sanil, N.K. is presently working as scientist under the Fish Health Section of the Marine Biotechnology Division at the Central Marine Fisheries Research Institute (CMFRI), Cochin, India. Has expertise in the field of parasitology, fish and shellfish pathology, molecular taxonomy of fish pathogens and electron microscopy. Did his masters in Zoology with specialization in Parasitology from University of Calicut and have more than 20 research publications in national and international journals.

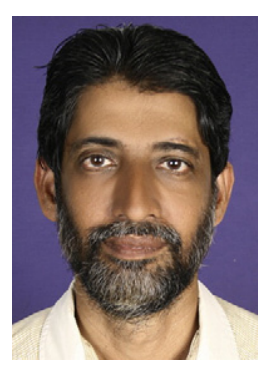

Asokan, P.K. is presently working as senior scientist under the Mariculture Division at the Calicut Research Center of the Central Marine Fisheries Research Institute. He has been working in the field of molluscan biology and mariculture for the past 25 years. He did postgraduation in mariculture at CAS in Mariculture from CMFRI in 1982 and has published more than 35 papers in national and international journals.

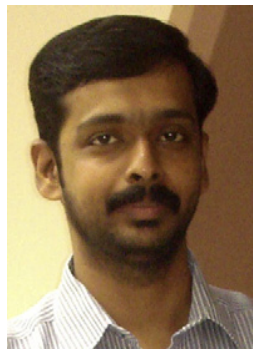

Lijo John is a Senior Research Fellow in the Marine Biotechnology Division of Central Marine Fisheries Research Institute. His broad area of interest is genetics and genomics. Did his masters in Biotechnology from Madurai Kamaraj University and has been working on the molecular taxonomy, population and evolutionary genetics of freshwater fishes and has published three papers.

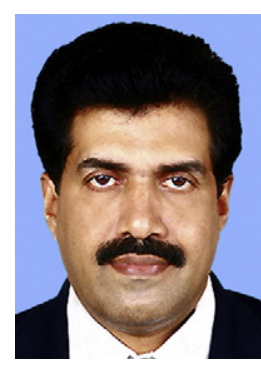

Vijayan, K.K. is presently working as principal Scientist and Head, Marine Biotechnology Division of the Central Marine Fisheries Research Institute (CMFRI), Cochin, India. Has been working in the field of shrimp physiology, fish health and Molecular Biology for the past 18 years. He did his postdoctoral research at the Gulf Coast Research Laboratory (GCRL), Institute of Marine Sciences, USM, USA and University of Liege \& University of Namur, Belgium, EU Has more than 30 research publications in national and international journals and won the prestigious national award for product development and commercialization in biotechnology from Department of Biotechnology, Govt of India for the Year 2003. He is also a reviewer for many Indian and International journals in the field of Fish health \& Aquaculture biotechnology. 